\title{
ESTIMATION OF BODY WEIGHT AND STATURE IN LATVIAN HOSPITALIZED SENIORS
}

\author{
Aija Balode ${ }^{1}$, Anda Stolarova ${ }^{2}$, Anita Villerusa ${ }^{3}$, \\ Daina Zepa ${ }^{4}$, Imants Kalnins ${ }^{5}$, Janis Vētra ${ }^{1}$ \\ ${ }^{1}$ Department of Morphology, Riga Stradins University, Riga, \\ ${ }^{2}$ Faculty of Medicine, Riga Stradins University, Riga, Latvia \\ ${ }^{3}$ Department of Public Health and Epidemiology, Riga Stradins University, \\ Riga, Latvia \\ ${ }^{4}$ Gerontology Centre, Riga East University Hospital, Riga, Latvia \\ ${ }^{5}$ Department of Physics, Riga Stradins University, Riga, Latvia
}

\begin{abstract}
Introduction. Weight and height are important measurements for many medical procedures. They are difficult to measure in bedridden patients. They can be estimated through equations based on anthropometric measurements generated in other countries, however their adequacy in different ethnical groups has been poorly studied.

Objective. To confirm the adequacy of formulae suggested in literature and to develop weight and height predicting equations for Latvian hospitalized seniors which use a tapeline as only tool and include no more than one measurement require turning bedridden patient.

Methods. Anthropometric measurements were taken from hospitalized seniors ( $\geq 65$ years) admitted to the Gerontology Centre, Riga East University Hospital. Actual body height and weight were compared with their estimates calculated from Chumlea, Rabito, Bernal, Lorenz, Crandell equations. Multiple linear regression analysis was used to create weight and height predictive models. The estimated and actual values were compared through a paired sample t-test.
\end{abstract}

Results. 223 hospitalized seniors, 169 women and 54 men, were assessed. There was no significant difference between actual and estimated mean weight by Rabito in females. The Chumlea formula estimated height in both genders. The Chumlea, Bernal underestimated, but Lorenz and Crandell 
formula overestimated the mean weight. The best weight predictive models which included only circumference measurements and no more than one measurement requiring to turn bedridden patients were $0.709^{*}$ abdominal circumference $+1.425^{*}$ arm circumference $(\mathrm{AC})+1.083^{*}$ calf circumference (CC) $-68.968, \mathrm{R}^{2}=0.962$ for males and $0.853^{*}$ hip circumference+ $1.405^{\star} \mathrm{AC}+0.499^{\star} \mathrm{CC}-79.355, \mathrm{R}^{2}=0.870$ for females. The adjusted height formula was $76.146-4.961^{\star}$ gender- $0.151^{\star}$ age $+1.245^{\star}$ hemispan, $\mathrm{R}^{2}=0.732$.

Conclusions. The suitable equations for the studied population body weight estimation were Rabito and Chumlea equations but for females only. The height was predicted by the Chumlea formula in both genders and by the Rabito equation in males. The best predictive body weight model which uses circumference measurements from which only one requires to turn bedridden patients were created and differed in females and males in the use of hip or abdominal circumference respectively. The height estimating equation which uses a tapeline as the only tool was adjusted for the study population. Validation of created equations is needed in a larger Latvian senior population.

Keywords: anthropometry, body weight, elderly, seniors, stature

\section{INTRODUCTION}

Weight and height are important measurements for many medical and nutritional procedures, such as the administration of drugs and nutrients for enteral/ parenteral nutritional therapy, the calculation of GRF, etc. [8]. Errors of calculation occur when weight and height are estimated only by visual observation [3]. Only 9\% of patients in Alfred and Claufield hospitals were in $10 \%$ weight range of $70 \mathrm{~kg}$ weight [8].

Body weight and the BMI are also used to assess the nutrition status and the risk of cardiovascular disease and type 2 diabetes [1]. The prevalence of both malnutrition (38.7\% [13]) and overweight or obesity (34-40\% [21]) is high in hospitalized elderly patients.

Body weight and stature are difficult to measure in bedridden. One third of patients in the Gerontology Centre, Riga East University Hospital is bedridden. No means of measuring patient weight is available in the center. Scales integrated to hospital beds have been developed, however, they have high costs and are not usually available [15].

Many studies have sought to develop the methods to estimate body weight and height from the specific measurements of the body segments that can be measured in these patients such as arm, calf, abdominal and hip circumferences, knee height and skinfold thickness $[6,9,12,2,17,14]$. The formulae 
generated differ in the need of the equipment (caliper, anthropometer/pediatric stadiometer, measuring tape), precision, the number of measurements and the study population.

A major problem is to adapt these equations according to the validity and applicability criteria used for each ethnic group [18]. The first formulae were developed by Chumlea and colleagues. They used knee height and age for estimating stature [5] and middle arm circumference (MAC), calf circumference (CC), subscapular skinfold thickness (SST) and knee height (KH) [6] for estimating weight in elderly Caucasians. However, in Italy [9], China [12] and Mexican women [3] equations did not estimate accurately the body weight of the elderly and equations for their respective population have been proposed. Beranal et al [2], using a stepwise multiple regression, found the best weight prediction model in Mexican elderly women when tricipital skinfold thickness instead of subscapular skinfold thickness was used.

The objective of the study was to test the adequacy of the formulae suggested in the literature and develop equations, weight and height predicting equations from variables the measurement of which requires only a measuring tape for Latvian hospitalized seniors.

\section{MATERIALS AND METHODS}

The study was conducted in seniors hospitalized at the Gerontology center, Riga East University hospital. The inclusion criteria were age $\geq 65$ years, the ability to stand up and stand still during taking measurements and being able to answer questions. Those with amputated limbs were excluded. The measurements were made on both sides of the body by anthropology laboratory nurses during 2012-2014. In the case of difference between the left and the right side measurements, the smallest ones were taken in circumference measurements and the largest ones in length measurements. The study was approved by the Riga Stradins University Ethics Committee.

The parameters measured were: height $(\mathrm{H}, \mathrm{cm})$, knee height $(\mathrm{KH}, \mathrm{cm})[15]$ and weight $(\mathrm{W}, \mathrm{kg})$ using portable anthropometer GPM $( \pm 0.1 \mathrm{~cm})$ and Soehnle Medi Scale $( \pm 1 \mathrm{~kg}$, maximum capacity $150 \mathrm{~kg})$ respectively; hemi-span, calf, arm [16], abdominal, chest circumference, using a rigid tape with $0.1 \mathrm{~cm}$ graduation; bicipital, tricipital, suprailiac, subscapular skinfold thickness ( $\mathrm{mm}$ ) [4] were measured with a calibrated caliper GPM $( \pm 2 \mathrm{~mm})$. Abdominal circumference was measured as the narrowest circumference between the lower part of the rib cage and the suprailiac crest. Chest circumference was measured along 
the inferior angle of the scapula on the back and the lower border of nipples in males and the 3rd ribs (above mammary glands) in females on the front. The subject weight and height were estimated by the formulae suggested in the literature. For details see Table 1.

Table 1. Equations to predict weight and height from anthropometric variables analyzed in the present study

\begin{tabular}{|c|c|}
\hline $\begin{array}{l}\text { Abbreviations } \\
\text { of equation }\end{array}$ & Equation \\
\hline $\mathrm{H}-\mathrm{Ch}[5]$ & Female: $84.88-(0.24 \times \mathrm{A})+(1.83 * \mathrm{KH})$ \\
\hline $\mathrm{H}-\mathrm{Ch}[5]$ & Male: $64.19-(0.04 * A)+(2.02 * \mathrm{KH})$ \\
\hline H-Ra [17] & $63.525-3.237(\mathrm{~S})-0.06904(\mathrm{~A})+1.293(\mathrm{HS})$ \\
\hline W-Ch [6] & Female: $\left(\mathrm{AC}^{*} 0.98\right)+\left(\mathrm{CC}^{*} 1.27\right)+\left(\mathrm{SST}^{*} 0.40\right)+\left(\mathrm{KH}^{*} 0.87\right)-62.35$ \\
\hline W-Ch [6] & Male: $\left(\mathrm{AC}^{*} 1.73\right)+(\mathrm{CC} * 0.98)+\left(\mathrm{SST}^{*} 0.37\right)+\left(\mathrm{KH}^{*} 1.16\right)-81.69$ \\
\hline W-Ra-1 [17] & $0.5030(\mathrm{AC})+0.5634(\mathrm{AbC})+1.3180(\mathrm{CC})+0.0339(\mathrm{SST})-43.1560$ \\
\hline W-Ra-2 [17] & $0.4808(\mathrm{AC})+0.5646(\mathrm{AbC})+1.3160(\mathrm{CC})-42.2450$ \\
\hline W-Ra-3 [17] & $0.5759(\mathrm{AC})+0.5263(\mathrm{AbC})+1.2452(\mathrm{CC})-4.8689(\mathrm{~S})-32.9241$ \\
\hline W-Be [2] & female $1,599^{*} \mathrm{KH}+1,135^{*} \mathrm{MAC}+0,735^{*} \mathrm{CC}+0,621 * \mathrm{TST}-83,123$ \\
\hline W-Cr [7] & $\begin{array}{l}\text { female: }-64.6+2.15^{*} \mathrm{AC}+0.54^{*} \mathrm{H} \\
\text { male: }-93.2+3.29^{*} \mathrm{AC}+0.43^{*} \mathrm{H}\end{array}$ \\
\hline W-Lo [14] & $\begin{array}{l}\text { males: }-137.432+\mathrm{H}^{*} 0.60035+\mathrm{AbC}^{*} 0.785+\mathrm{HC}^{*} 0.392 \\
\text { females: }-110.924+\mathrm{H}^{*} 0.4053+\mathrm{AbC}^{*} 0.325+\mathrm{HC}^{*} 0.836\end{array}$ \\
\hline
\end{tabular}

H - height, W - weight, Ch - Chumlea et al, Ra - Rabito et al, Be - Bernal et al, Cr - Crandall et al, Lo - Lorenz et al, A - age, KH - knee height, AL - arm length, HS - hemispan, S - sex (1 - male and 2 - female), AC arm circumference, Ab - abdominal circumference, CC - calf circumference, SST - subscapular skinfold, TST - tricipital skinfold, HC - hip circumference. Circumference and length measurements in $\mathrm{cm}$, skinfolds in $\mathrm{mm}$, and weight in $\mathrm{kg}$.

The anthropometric measurements were used to compare the actual and estimated by formulae suggested in the literature body weight and height values and for creating weight and height predictive models. The actual weight and height were compared with the estimated ones by the paired sample t-test. The measurements between the independent sample groups were compared with the independent sample t-test. The strength of association between measurements was measured by the Pearson correlation coefficient. Equations for weight and height estimation were obtained by multiple linear regressions. For enhancing the applicability of the predictive models no more than one variable, the measurement of which requires turning a bedbound patient, was included. Data was analyzed using SPSS-22. 


\section{RESULTS}

223 hospitalized patients fulfilled the inclusion criteria. The majority (169; $76 \%$ ) of the sample were females. The age, body weight, height and the BMI of males and females are summarized in Table 2. The independent sample t-test showed statistically significantly differences between males and females for stature and body weight.

Table 2. Summary of descriptive statistics of hospitalized seniors

\begin{tabular}{lcccc}
\hline & All (223; 100\%) & Female (169; 76\%) & Male (54; 24\%) & $p$ value \\
\hline Age, years & $79 \pm 6$ & $79 \pm 8$ & $78 \pm 6$ & 0.153 \\
\hline Body weight, kg & $75 \pm 16$ & $73 \pm 15$ & $82 \pm 19$ & 0.002 \\
\hline Stature, cm & $160.0 \pm 8.8$ & $156.7 \pm 6.9$ & $170.0 \pm 5,6$ & $<0.001$ \\
\hline BMl, kg/m $/ \mathrm{m}^{2}$ & $29.3 \pm 5.4$ & $29.3 \pm 5.2$ & $28.2 \pm 5.7$ & 0.940 \\
\hline
\end{tabular}

Table 3 shows statistical information regarding actual and estimated body weight measures according to different methods adopted. With respect to weight regarding all the sample the paired sample $t$-test indicated that the estimated measures did not differ significantly from actual when calculated by W-Ra-1 formula. Concerning all the sample formulae created by Chumlea (W-Ch), Rabito (W-Ra-2, W-Ra-3) underestimated, but Lorenz (W-Lo) and Crandall (W-Cr) formulae overestimated the weight. The greatest differences were obtained by the Chumlea formula (W-Ch) which underestimated the actual mean body weight by $8.9 \mathrm{~kg}$ in females and $10 \mathrm{~kg}$ in males. When the estimated and actual body weight measures were compared in females both W-ra-1 and W-Ra-2 equations did not show statistically significant mean differences. In females the weight was underestimated by Chumlea (W-Ch), Bernal (W-Be), Rabito (W-Ra-3) equations, but overestimated by Lorenz (W-Lo) and Crandell (W-Cr) equations. All the equations showed statistically significant mean differences in males. The formula developed by Lorenz et al (W-Lo) showed the closest measures of actual weight in males (mean difference $1.2 \mathrm{~kg}$ ). In males the weight was underestimated by Chumlea, Rabito (W-Ra-1, W-Ra2, W-Ra-3) and Crandell (W-Cr) equations. 
Table 3. Comparison between actual and estimated body weight $(\mathrm{kg})$ and height $(\mathrm{cm})$ measurements by formulae suggested in literature of hospitalized adults

\begin{tabular}{|c|c|c|c|c|c|c|c|c|c|c|c|c|}
\hline Formula & Mean & $S D$ & $M D$ & $p$ & Mean & $S D$ & & $p$ & Mean & $S D$ & & $p$ \\
\hline \multicolumn{5}{|c|}{ All (male and female) } & \multicolumn{4}{|c|}{ Male } & \multicolumn{4}{|c|}{ Female } \\
\hline $\begin{array}{l}\text { Actual } \\
\text { weight }\end{array}$ & 75 & 16 & & & 82 & 19 & & & 73 & 15 & & \\
\hline W-Ch [6] & 66 & 12 & -9.2 & $<0.001$ & 72 & 15 & -10.0 & $<0.001$ & 64 & 10 & -8.9 & $<0.001$ \\
\hline W-Ra-1 [17] & 74 & 12 & -0.8 & 0.100 & 76 & 14 & -5.4 & $<0.001$ & 74 & 11 & 0.7 & 0.254 \\
\hline W-Ra-2 [17] & 74 & 12 & -1.2 & 0.018 & 76 & 14 & -5.7 & $<0.001$ & 73 & 11 & -0.2 & 0.699 \\
\hline W-Ra-3 [17] & 71 & 12 & -4.0 & $<0.001$ & 77 & 13 & -5.0 & $<0.001$ & 69 & 11 & -3.7 & $<0.001$ \\
\hline W-Lo [14] & 78 & 14 & 2.6 & $<0.001$ & 85 & 16 & 1.6 & $<0.001$ & 76 & 12 & 2.5 & $<0.001$ \\
\hline $\mathrm{W}-\mathrm{Cr}[7]$ & 80 & 12 & 4.5 & $<0,001$ & 73 & 15 & -9.2 & $<0.001$ & 82 & 10 & 8.9 & $<0.001$ \\
\hline W-Be [2] & NA & NA & NA & NA & NA & NA & NA & NA & 65 & 10 & -7.5 & $<0.001$ \\
\hline $\begin{array}{l}\text { Actual } \\
\text { height }\end{array}$ & 160.0 & 8,8 & 160.0 & & 170.1 & 5.6 & & & 156.7 & 6.9 & & \\
\hline $\mathrm{H}-\mathrm{Ch}[5]$ & 160.0 & 7.6 & 160.0 & 0.912 & 169.8 & 5.4 & -0.33 & 0.449 & 156.9 & 5.2 & 0.14 & 0.644 \\
\hline H-Ra [17] & 160.8 & 7.0 & 160.8 & 0.007 & $\mid 170.0$ & 5.0 & -0.42 & 0.417 & 158.0 & 4.7 & 1.26 & 0.001 \\
\hline
\end{tabular}

MD - mean difference (actual- estimated), W-weight, $\mathrm{H}$ - height, $\mathrm{Ch}$ - Chumlea et al, Ra - Rabito et al, Cr Crandall et al, Lo - Lorenz et al, Be - Bernal et al

With respect to height there was no significant difference between the actual and estimated measures by Chumlea $(\mathrm{H}-\mathrm{Ch})$ both in males and females. The Rabito (H-Ra) equation predicted the height in males but not in females and mixed sample. See Table 3.

There was significant correlation between circumference measurements and body weight. The coefficients arranged from the largest to the smallest: for males chest circumference 0.939 , abdominal -0.937 , hip -0.926 , calf -0.899 , arm -0.827 , for females hip circumference 0,906 , chest -0.875 , abdominal 0.808 , arm -0.831 , calf circumference $0.690, \mathrm{p}<0.05$. As correlation coefficients differed in males and females, we performed the multiple linear regression analysis for creating weight predictive equations in both genders. The measurements used required a tapeline as the only tool. They included arm and calf circumference and only one measurement which required turning bedridden patients- chest or abdominal or hip circumference. Six models were made in females and males. The best was the predictive model in females as turning 
bedridden patient requiring variable included hip circumference in females and abdominal circumference in males. See Table 4.

Table 4. Weight predicting equations obtained in the study from circumference measurements in hospitalized seniors

\begin{tabular}{|c|c|c|c|c|}
\hline Sex & C.m.r.t.b.p. & O.c. m. & Weight predicting equations & $\mathbf{R}^{2}$ \\
\hline \multirow{3}{*}{ Female } & $\mathrm{HC}$ & \multirow[t]{6}{*}{$A C, C C$} & W-a-1 $0.853^{*} H C+1.405^{*} A C+0.499^{*} C C-79.355$ & 0.870 \\
\hline & $\mathrm{AbC}$ & & W-a-2 $0.488^{*} A C+1.975^{*} A C+0.786^{*} C C-58.914$ & 0.830 \\
\hline & $\mathrm{ChC}$ & & W-a-3 $0.788^{*} \mathrm{ChC}+1.559^{*} \mathrm{AC}+0.758^{*} \mathrm{CC}-79.083$ & 0.862 \\
\hline \multirow{3}{*}{ Male } & $\mathrm{HC}$ & & W-a-4 0.898*HC+1.271*AC+0.499*CC-79.355 & 0.937 \\
\hline & $\mathrm{AbC}$ & & W-a-5 $0.709^{*} A b C+1.425^{*} A C+1.083^{*} C C-68.968$ & 0.962 \\
\hline & $\mathrm{ChC}$ & & W-a-6 $0.878^{*} \mathrm{ChC}+1.352^{*} \mathrm{AC}+1.033^{*} \mathrm{CC}-87.673$ & 0.949 \\
\hline
\end{tabular}

C.m.r.t.b.p. - circumference measurements requires turning bedbound patient, o.c.m. - other circumference measurements, $\mathrm{HC}$ - hip circumference, AC - arm circumference, AbC - abdominal circumference, $\mathrm{ChC}$ - chest circumference. Measurements in $\mathrm{cm}$, estimated weight in $\mathrm{kg}$.

The adjusted to the sample stature predicting equation similar to $\mathrm{H}$-Ra with variables measurement of which requires a tapeline only was $76.146-4.961^{\star}$ sex$0.151^{\star}$ age $+1.245^{\star}$ hemi-span, $\mathrm{R}^{2}=0.732$.

\section{DISCUSSION}

Simple anthropometric measurements may be used for the estimation of body weight and stature in bedbound patients. The number of seniors is rising in developed countries. The elderly more often suffer from immobility associated disorders such as stroke, frailty and hip fractures [11]. Because of high prevalence of bedridden patients in the Gerontology center at Riga East University hospital there is an increasing need for available solutions to predict body weight and stature.

In relation to weight the present study did not show a significant difference between actual and estimated weight measures only in females when estimated by W-Ra-1 and W-Ra-2 [17] equations. Other authors did not find significant difference between actual and estimated weight by W-Ra-1, 2, 3 [17] and the Chumlea formulae in both sexes $[15,19]$. In the study of Sampaio et al [20] there was no significant difference between actual and estimated weight by Chumlea formula in Fortalenza, Brazilian adults and the elderly. The possible explanation, why Sampaio et al [20] obtained concordant results for weight 
estimation by the Chumlea formula and our study did not, was that the mean BMI of Fortalenza patients $\left(22 \mathrm{~kg} / \mathrm{m}^{2}\right)$ was lower compared to the present patients $\left(29 \mathrm{~kg} / \mathrm{m}^{2}\right)$.

Similar to our study Rabito et al [17] aimed at obtaining an equation from measurements which require only a measuring tape to estimate weight. In contradistinction to them we assessed also chest and hip circumference. Chest circumference in males and hip circumference in females showed the strongest association with body weight. We performed multiple linear regression analysis in both genders to create six models which included arm and calf circumference and only one variable which requires turning bedbound patient- hip, abdominal or chest circumference. The best predictive model in females included hip circumference, but in males abdominal circumference. The resulting variables in best male predictive equation- arm, calf and abdominal circumference- were the same as in Rabito W-Ra-2 [17] equation.

With regard to height the present study found no significant differences when comparing actual height measurements to those estimated by Chumlea et al. Other studies also found similar results in males only [15] and both in males and females [4]. Previous studies [15] found statistically significant mean differences between actual and estimated height measures both in males and females when estimated by Rabio et al. Our study did not show significant mean differences between actual and estimated height by Rabito et al $(\mathrm{H}-\mathrm{Ra})$ [17] in males but not in females. Because of that we performed multiple regression analysis in order to adjust $\mathrm{H}$-Ra equation to the Latvian senior population studied from variables which are measured by a tapeline only.

\section{CONCLUSIONS}

The suitable equations obtained in the literature for the studied population body weight estimation were Rabito and Chumlea equations but for females only. The height was predicted by Chumlea formula in both genders and by Rabito equation in males only. The best predictive body weight model which uses circumference measurements from which only one requires turning bedridden patients were created and differed in females and males in the use of hip or abdominal circumference respectively. The height estimating equation which uses a tapeline as the only tool was adjusted for the study population. The validation of created equations is needed in a larger Latvian senior population. 


\section{REFERENCES}

1. Bays H.E., Chapman R.H., Grandy S. (2007). The relationship of body mass index to diabetes mellitus, hypertension and dyslipidaemia: comparison of data from two national surveys. International Journal of Clinical Practice, 61, 5, 737-747. http://www.ncbi.nlm.nih.gov/pmc/articles/PMC1890993/

2. Bernal-Orozco M.R.., Vizmanos B., Hunot C., Flores-Castro M., Leal-Mora D., Cells A., Fernindez-Ballart J.D. (2010). Equation to estimate body weight in elderly Mexican women using anthropometric measurements. Nutr Hosp, 25, 4, 648-655. http://scielo.isciii.es/scielo.php?script=sci_arttext\&pid=S0212161 12010000400018\&lng=en\&nrm=iso\&tlng=en

3. Bloomfield R., Steel E., MacLennan G., Noble D.W. (2006). Accuracy of weight and height estimation in an intensive care unit: implications for clinical practice and research. Crit Care Med, 34, 2153-2157. http://portalbiocursos.com.br/ ohs/data/docs/57/98-_Accuracy_of_weight_and_height_estimation_in_an_ intensive_care_unit__Implications_for_clinical_practice_and_research.pdf

4. Cereda E., Bertoli S., Battezzati A. (2010). Height prediction formula for middle-aged (30-55y) Caucasians. Nutrition, 26, 11-12, 1075-1081.

http://www.ncbi.nlm.nih.gov/pubmed/20036515

5. Chumlea W.C, Roche A.F., Steinbaugh M.L. (1985). Estimating stature from knee height for persons 60 to 90 years of age. J Am Geriatr Soc, 33, 5, 116-120.

6. Chumlea W.C., Guo S., Roche A.F., Steinbaugh ML. (1988). Prediction of body weight for the non-ambulatory elderly from anthropometry. J Am Diet Assoc, $88,5,564-568$.

7. Crandall C.S., Gardner S, Braude DA. (2009). Estimation of total body weight in obese patients. Air Med J, 28, 139-145. http://www.ncbi.nlm.nih.gov/pubmed/19414107

8. Darnis S., Fareau N., Corallo C.E., Poole S., Dooley M.J., Cheng A.C. (2012). Estimation of body weight in hospitalized patients. Q J Med, 105, 769-774. http://qjmed.oxfordjournals.org/content/105/8/769.long

9. Donini L.M., De Felice M.R, De Bernardini L., Ferrari G., Rosano A. (1997). Applicabilité à une population italienne agée des formules de prédiction du poids et de la taille. Age et Nutrition, 8, 104.

10. Durnin J.V, Womersley J. (1974). Body fat assessed from total body density and its estimation from skinfold thickness: measurements on 481 men and women aged from 16 to 72 years. Br J Nutr, 32, 77-97. http://journals.cambridge.org/ download.php ?file=\%2FBJN\%2FBJN32_01\%2FS0007114574000614a.pdf\&c ode $=$ fe13b6637b83ce3ed69390f92ddf4fcd

11. Graafmans W.C., Ooms M.E., Hofstee H.M.A, Bezemer P.D. (1996). Falls in the Elderly: A Prospective Study of Risk Factors and Risk Profiles. American Journal of Epidemiology, 143, 11, 1129-1136.

http://aje.oxfordjournals.org/content/143/11/1129 
12. Jung M.Y., Chan M.S., Chow V.S., Chan Y.T., Leung P.F., Leung E.M. (2004). Estimating geriatric patient's body weight using the knee height caliper and mid-arm circumference in Hong Kong Chinese. Asia Pac J Clin Nutr, 13, 261 264. http://apjcn.nhri.org.tw/server/APJCN/13/3/261.pdf

13. Kaiser M.J., Bauer J.M., Rämsch C. (2010). Frequency of malnutrition in older adults: a multinational perspective using the mini nutritional assessment. J Am Geriatr Soc, 58, 9, 1734-1738. http://www.ncbi.nlm.nih.gov/pubmed/20863332

14. Lorenz M.W., Graf M., Henke C., Hermans M. (2007). Anthropometric approximation of body weight in unresponsive stroke patients. J Neurol Neurosurg Psychiatry, 78, 1331-1336. http://www.ncbi.nlm.nih.gov/pmc/articles/ PMC2095625/

15. Melo A.P.F., Kuerten de Salles R., Vieira F.G.K., Ferreira M.G. (2014). Methods for estimating body weight and height in hospitalized adults: a comparative analysis. Rev Bras Cineantropom Desempenho Hum, 16, 4, 475-484.

http://www.scielo.br/pdf/rbcdh/v16n4/en_1980-0037-rbcdh-16-04-00475.pdf

16. Quiroz-Olguín G., Serralde-Zúñiga A.E., Saldaña-Morales V., Guevara-Cruz M. (2013). Validation of a new formula for predicting body weight in a Mexican population with overweight and obesity. Nutr Hosp, 28, 3, 690-693.

17. Rabito E.I., Vanucchi G.B., Suen V.M., Neto L.L., Marchini J.S. (2006). Weight and height prediction of immobilized patients. Rev Nutr, 19, 6, 655-661. http:// www.scielo.br/scielo.php?pid=S1415-52732006000600002\&script=sci_arttext

18. Rabito E.I., Mialich M.S., Martínez E.Z., García R.W., Jordao A.A., Marchini J.S. (2008). Validation of predictive equations for weight and height using a metric tape. Nutr Hosp, 23, 614-618. http://scielo.isciii.es/scielo.php?script=sci_artte xt\&pid=S021216112008000800014\&lng=en\&nrm=iso\&tlng=en

19. Rezende F.A.C., Rosado L.E.F.P.L., Franceschinni S.C.C., Rosado G.P., Ribeiro R.C.L. (2009). Avaliação da aplicabilidade de fórmulas preditivas de peso e estatura em homens adultos. Rev Nutr, 22, 4, 443-451.

http://www.scielo.br/pdf/rn/v22n4/v22n4a01.pdf

20. Sampaio H.A.C., Melo M.L.P., Almeida P.C., Benevides A.B.P. (2002). Aplicabilidade das fórmulas de estimativa de peso e altura para adultos e idosos. Rev Bras Nutr Clin, 17, 4, 117-121.

21. Singh P., Kapil U., Dey A.B. (2004). Prevalence of overweight and obesity amongst elderly patients attending a geriatric clinic in a tertiary care hospital in Delhi, India. Indian J Med Sci, 58, 162-163. http://www.indianjmedsci.org/ text.asp?2004/58/4/162/8290

\section{Address for correspondence to:}

Aija Balode

Department of Morphology, Riga Stradins University

Kronvalda bulvaris 9, LV-1010, Latvia

E-mail: aija.balode@rsu.lv 